\title{
Corrigendum
}

\section{Corrigendum to "CC_TRS: Continuous Clustering of Trajectory Stream Data Based on Micro Cluster Life"}

\author{
Musaab Riyadh (D), ${ }^{1,2}$ Norwati Mustapha, ${ }^{1}$ \\ Md. Nasir Sulaiman, ${ }^{1}$ and Nurfadhlina Binti Mohd Sharef ${ }^{1}$ \\ ${ }^{1}$ Faculty of Computer Science and Information Technology, Universiti Putra Malaysia, Serdang, Selangor, Malaysia \\ ${ }^{2}$ Department of Computer, College of Science, Mustansiriyah University, Baghdad, Iraq
}

Correspondence should be addressed to Musaab Riyadh; m.shibani1968@gmail.com

Received 11 December 2017; Accepted 13 December 2017; Published 9 January 2018

Copyright (c) 2018 Musaab Riyadh et al. This is an open access article distributed under the Creative Commons Attribution License, which permits unrestricted use, distribution, and reproduction in any medium, provided the original work is properly cited.

In the article titled "CC_TRS: Continuous Clustering of Trajectory Stream Data Based on Micro Cluster Life" [1], there was a missing affiliation for the first author. The revised authors' list and affiliations are shown above.

\section{References}

[1] M. Riyadh, N. Mustapha, M. N. Sulaiman, and N. B. M. Sharef, "CC_TRS: Continuous Clustering of Trajectory Stream Data Based on Micro Cluster Life," Mathematical Problems in Engineering, vol. 2017, Article ID 7523138, 9 pages, 2017. 


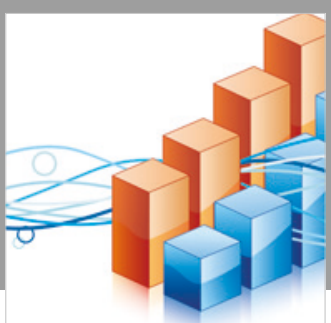

Advances in

Operations Research

\section{-n-m}
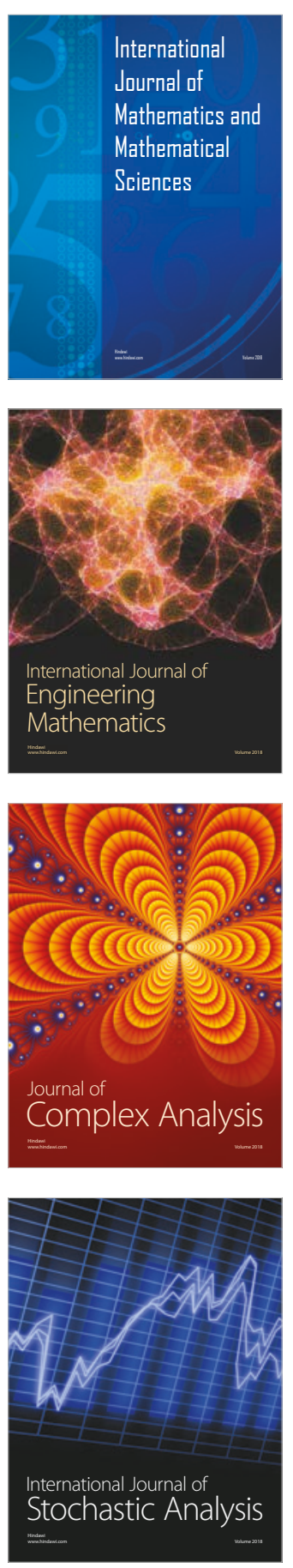
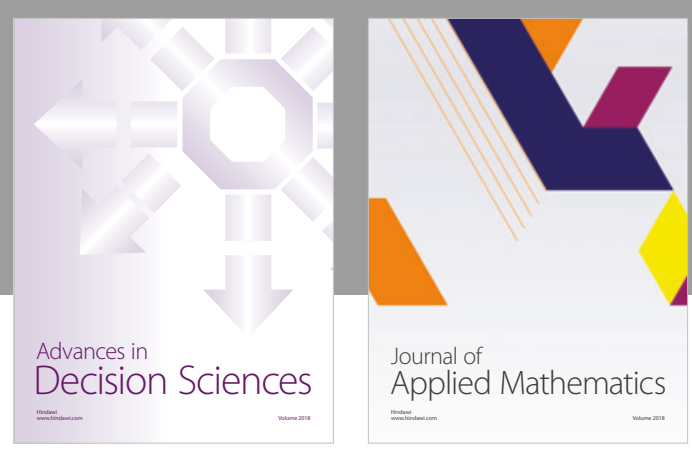

Journal of

Applied Mathematics
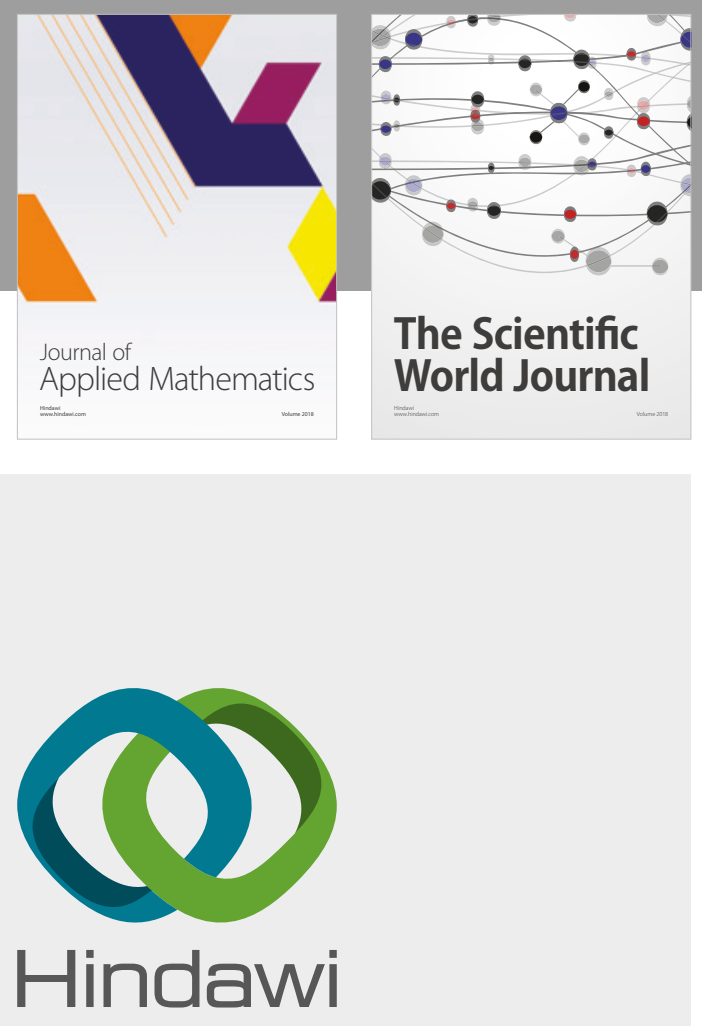

Submit your manuscripts at

www.hindawi.com

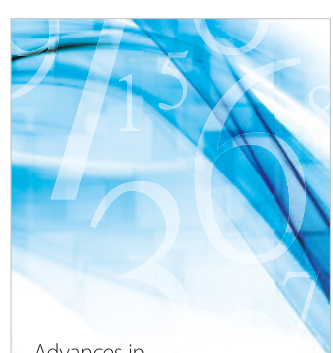

Advances in
Numerical Analysis
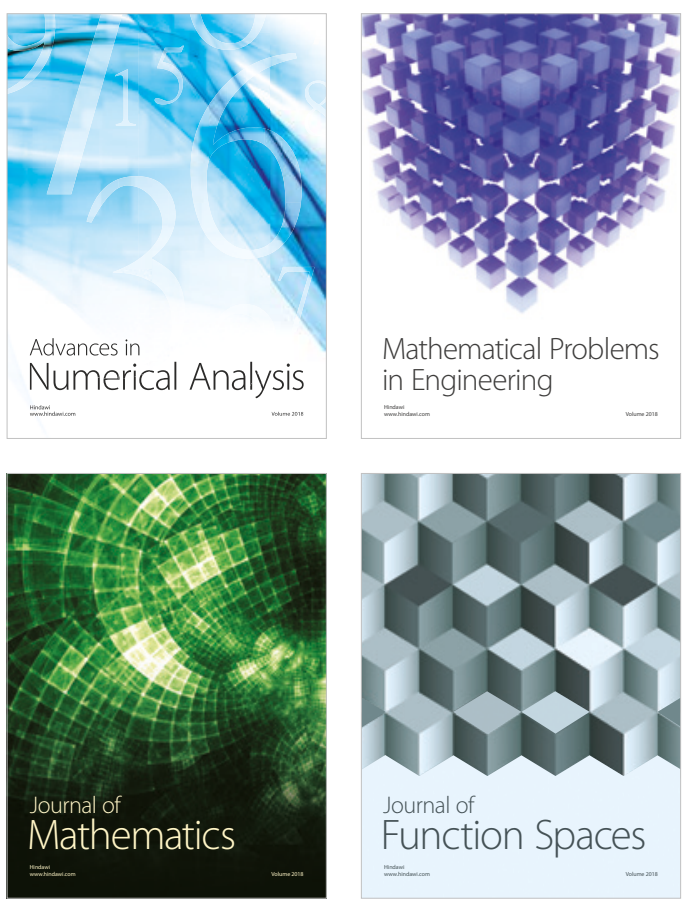

Mathematical Problems in Engineering

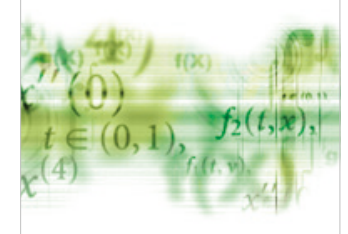

International Journal of

Differential Equations

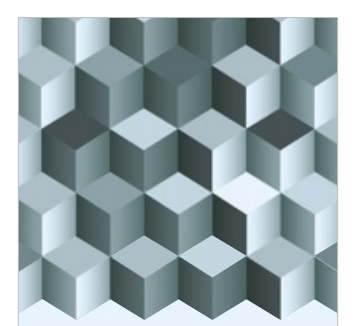

Journal of

Function Spaces

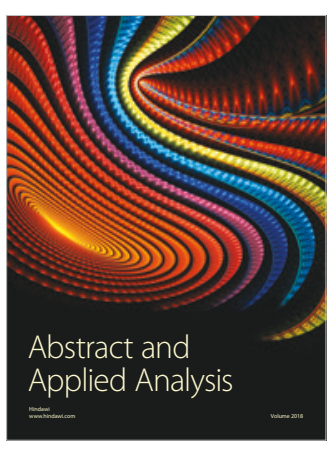

The Scientific

World Journal

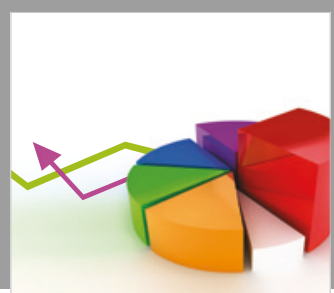

Journal of

Probability and Statistics
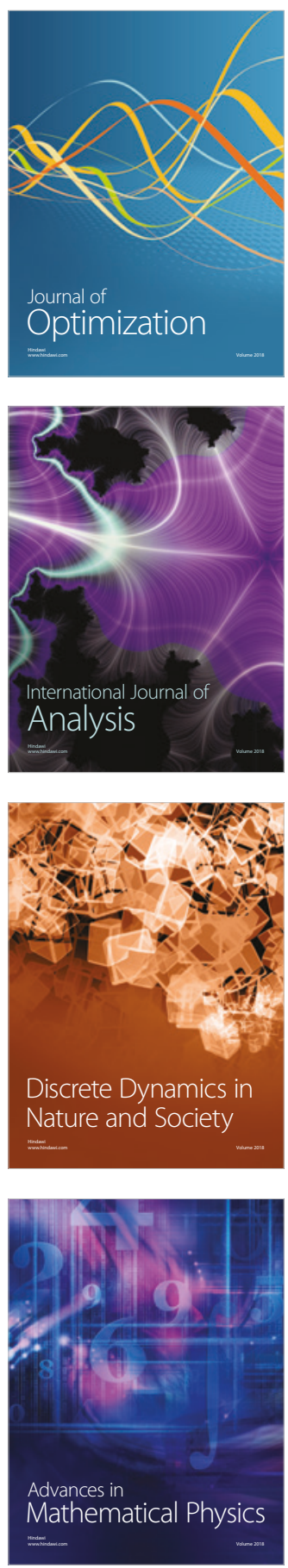